\title{
Effect of Antenatal Exercise Teaching Program on Neonatal Outcomes During Delivery in Erbil, Iraq
}

\author{
Warda Hassan Abdullah ${ }^{1}$, Badia Mohammed Najib ${ }^{1}$ \\ ${ }^{1}$ Department of Midwifery, College of Nursing, Hawler Medical University, Erbil, Kurdistan Region, Iraq
}

\begin{abstract}
Background:Antenatal exercises are safe and beneficial for the fetus, and neonatal health, wellbeing, were positive effect on neonatal outcomes during delivery, such as prevent fetal distress, remained the Apgar score and birth weight in normal range level. The aim of this study was to determine the effect of antenatal exercise classes on the neonatal outcomes during delivery. Methods: prospective -Interventional study was conducted in Maternal - Child Health Department in Najdi Heydari Health Care Center, Maternity and Razgary Teaching Hospitals / Erbil City / Kurdistan region / Iraq. One hundred and twelve healthy pregnant women. One half of the pregnant women were included in the intervention group $(n=56)$ and the other half in the control group $(n=56)$. The intervention group was educated about antenatal exercises. While the control group remained on standard maternal health care program (without exercise classes). Neonatal outcomes evaluated from documents of birth registry and mothers interview in the postpartum ward using a special check list prepared for that purposed.

Results: In the original data, there was a statistically significant difference between both groups. Regarding the fetal heart rate $(\mathrm{P}<0.01)$, Apgar score $(\mathrm{P}<0.004)$, neonatal complications $(\mathrm{P}<0.039)$, admission neonatal intensive care unit $(\mathrm{P}<0.003)$ through the progress of delivery. in other hand, not a statistically significant difference between intervention and control groups concerning neonatal weight. Conclusion: Antenatal exercise is recommended for healthy pregnant women as a safe and effective strategy, enhance the neonatal outcomes during the delivery process.
\end{abstract}

Key words: antenatal exercise, teaching program, neonatal outcomes

\section{Introduction}

The pregnancy phase is an interval of growth, development, and physiological change in mother and fetus ${ }^{1}$. In uncomplicated pregnancies, women with or without a previously sedentary lifestyle should be encouraged to take part in aerobic and strength class exercises as a part of a healthy lifestyle ${ }^{1}$. Both the American College of Obstetricians and Gynecologists and the Society of Obstetricians and Gynecologists of Canada currently recommend that in the absence of complications during pregnancy, pregnant women should exercise for half hour at a moderate intensity on

\footnotetext{
Corresponding author:

Warda Hassan Abdullah

E-mail: warda.abdullah@hmu.edu.krd

Warda.hassan2014@gmail.com
}

most, if not all, days of the week $3,4,5$. Many evidences showed there was a significant effect of exercise training during the course of pregnancy on the fetal heart rate, fetal complications during labor and neonatal Apgar score ${ }^{6,7,8}$, and the effect of exercise during pregnancy on the newborn's birth weight is unclear ${ }^{9,10}$. Moderate to high level of continues maternal exercise have been associated with reduced birth weight ${ }^{11}$. A few studies ${ }^{12,13}$ have found reduced birth weight among women who continue vigorous exercise during pregnancy compared with those who discontinue the exercise or who are sedentary.

In this study, we amid to evaluate the effectiveness of antenatal exercise classes on the neonatal outcomes during delivery in Erbil City / Kurdistan Region / Iraq.

\section{Materials and Method}

Tools for collecting data included the following: 
assessment form was constructed by the researcher based on the literature and recommendations of antenatal exercises by the American College of Obstetrics and Gynecologists, 2015 14 , that included identifying demographic data, obstetrical history, assessment contraindications during pregnancy of the participants and checklist form. Content validity and reliability was secured. The sample size was calculated as 112 subjects based on PS program (power and sample size calculation) version 3.0.43. Who was attending the Maternal - Child Health Department in Najdi Heydari Health Care Center, Maternity and Razgary Teaching Hospitals, Erbil City, Kurdistan Region, Iraq. The subjects were selected using accessible sampling. The inclusion criteria were the following: age 18 - 40 years old, gestational age 17- 36, single tone pregnancy. Exclusion criteria were: free from contraindications of performing an exercise during pregnancy based on recommended of the American College of Obstetricians and Gynecologists (ACOG),2015 ${ }^{4}$, as an obstetrician assessed all study participant subjects who had any medical health problem or pregnancy complications were excluded from the study. Subjects were purposely divided into intervention group 56 and control group 56. The intervention group was divided into nine subgroups and required to attend exercise classes for one hour weekly for four weeks. The purpose of the study was explained to all subjects in both groups then informed consents were taken from them, and they completed the basic information forms which were prepared by researchers. The classes include the following:

1-Benefits, counterindications and discontinue of exercises during pregnancy.

2- Aerobic exercises and strength training of all the major muscle groups (walking or running and lower limbs relaxation exercise)

3- Pelvic floor exercises and birth ball exercise.

4- Coping in Labor (Helpful positions and breathing for labor).

During the classes demonstration of exercises and practical training, slides and pamphlets were used. All study participants were instructed to stopped exercises and reported immediately to the Maternity Teaching Hospital in the case of vaginal bleeding, abdominal contraction, vaginal fluid discharge. Participants in the control group received the routine care without attending classes. All participants who were unable to continue the program from both groups were excluded from the study finally subjects in the intervention group 48 and control group 49 Figure 1.

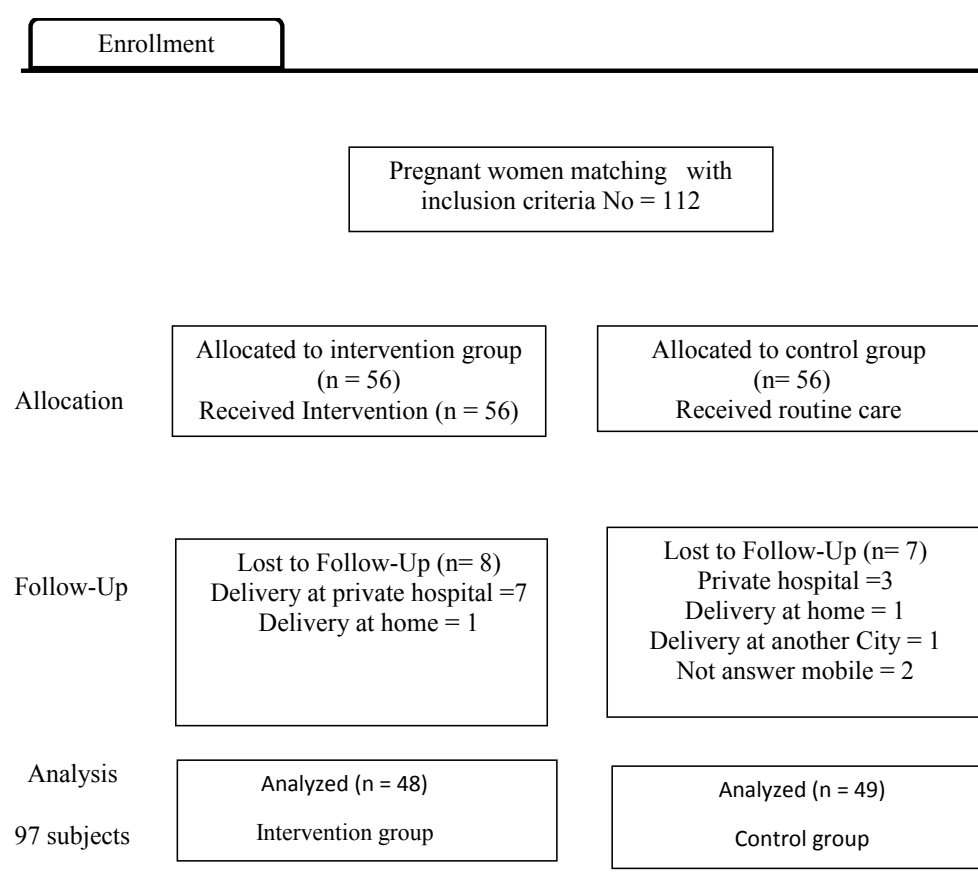

Fig 1. Flowchart of the participants through the study. 


\section{Outcomes and Statistical analysis}

The delivery outcome of the fetus and neonatal (fetal heart rate, fetal complications during labor, Apgar score, birth weight, and admission neonatal intensive care unit) was evaluated from documents of birth registry and mothers interview in postpartum ward using a special checklist prepared for that purpose. Statistical analysis was performed using SPSS for Windows version 20.0 software. Chi-square tests, ANOVA test, and Fisher exact were used for comparisons of intervention and control groups data. A value of $\mathrm{P}$ values $(<0.05)$ was accepted as statistically significant.

\section{Results}

The present study findings that highest percentage $(57.1 \%)(58.9 \%)$ of intervention and control groups respectively their age ranged between 20-29 years old and highest percentage (37\%) of the intervention group had six years schooling were $(32.1 \%)$ of the control group was Illiterate. The same table indicates that the highest percentage (91.1\%) (92.9\%) of both groups were housewives, respectively. Results also showed that demographic characteristic of both groups was homogeneous and no significant difference was observed between them regarding the age group, educational level and gravidity $(\mathrm{P}<0.978, \mathrm{P}<0.738, \mathrm{P}<0.849)$ respectively (Table 1).

Table 1: Demographic data of the study sample $\mathrm{N}=112$

\begin{tabular}{|c|c|c|c|}
\hline Variables & $\begin{array}{r}\text { IG }=56 \\
\text { No. }(\%)\end{array}$ & $\begin{array}{l}\text { CG }=56 \\
\text { No. }(\%)\end{array}$ & P-Value \\
\hline $\begin{array}{l}\text { Age (years) } \\
<20 \\
20-29 \\
40+\end{array}$ & $\begin{array}{l}6(10.7) \\
32(57.1) \\
18(32.1)\end{array}$ & $\begin{array}{l}6(10.7) \\
33(58.9) \\
17(30.4)\end{array}$ & 0.978 \\
\hline $\begin{array}{l}\text { Education level } \\
\text { Illiterate } \\
\text { Primary } \\
\text { Secondary } \\
\text { Institute \& College }\end{array}$ & $\begin{array}{l}13(23.2) \\
21(37.5) \\
12(21.4) \\
10(17.9)\end{array}$ & $\begin{array}{l}18(32.1) \\
17(30.4) \\
11(19.6) \\
10(17.9)\end{array}$ & 0.738 \\
\hline $\begin{array}{l}\text { Gravida } \\
1 \\
2-4 \\
=5+\end{array}$ & $\begin{array}{l}27(48.2) \\
22(39.3) \\
7(12.5)\end{array}$ & $\begin{array}{l}25(44.6) \\
22(39.3) \\
9(16.1)\end{array}$ & 0.849 \\
\hline
\end{tabular}

IG: Intervention group, CG: Control group

The highest percentage $97.9 \%$ of study sample their fetus heart rate was normal range rate of intervention group within compared to $81.6 \%$ of the control group. Which observed a statistically significant difference between intervention and control groups concerning pregnant women is fetal heart rate) $\mathrm{P}>0.01$ (, in favors of intervention as shown in (Table 2). 
Table 2: Comparison of the fetal heart rate during delivery between the two groups

\begin{tabular}{|l|l|l|l|}
\hline Variable & $\begin{array}{l}\text { IG (48) } \\
\text { No. (\%) }\end{array}$ & $\begin{array}{l}\text { CG (49) } \\
\text { No. (\%) }\end{array}$ & -P- Value \\
\hline $\begin{array}{l}\text { Fetal Heart Rate/ bpm } \\
>120\end{array}$ & $0(00)$ & $7(14.3)$ & \\
$120-160$ & $47(97.9)$ & $40(81.6)$ & 0.01 \\
$<160$ & $1(2.1)$ & $2(3.1)$ & \\
\hline
\end{tabular}

IG: Intervention group, CG: Control group, bpm: Beats per-minutes

Table 3 showed that $10.4 \%$ of the study sample in the intervention group had fetal distress within compared to $28.6 \%$ of control group, a statistically significant difference between intervention and control groups concerning neonatal complication) ( $\mathrm{P}>0.039)$, in favors of the intervention group.

Table 3: Comparison of the fetal complications during labor between the two groups

\begin{tabular}{|l|l|l|l|}
\hline Variables & $\begin{array}{l}\text { IG (48) } \\
\text { No. (\%) }\end{array}$ & $\begin{array}{l}\text { CG (49) } \\
\text { No. (\%) }\end{array}$ & -P- Value \\
\hline $\begin{array}{l}\text { Fetal distress } \\
\text { Non- complications }\end{array}$ & $5(10.4)$ & $14(28.6)$ & 0.039 \\
\hline
\end{tabular}

IG: Intervention group, CG: Control group

Table 4 indicated that highest percentage (93.8\%) of the neonatal their Apgar score higher than 7 scores in intervention group within compared to $71.4 \%$ of control group, a statistically significant difference between intervention and control groups concerning neonatal Apgar score ( $\mathrm{P}>0.004)$, in favors of the intervention group. The same table showed that higher percentage $(89.6 \%)$ of the neonatal in the intervention group their body weight between 2500 to $<4000 \mathrm{mg}$ within compared to $89.8 \%$ the control group, while $89.8 \%$ of the neonatal their body weight between 2500 to $<4000 \mathrm{~g}$, not a statistically significant difference between intervention and control groups concerning neonatal weight $(\mathrm{P}<1.00)$. In addition, only $8.3 \%$ of the neonatal admission to intensive care unit in the intervention group within compared to $32.7 \%$ of control group, a statistically significant difference between intervention and control groups concerning neonatal admitted care unit $(\mathrm{P}>0.003)$, in favors of the intervention group.

Table 4: Comparison of the neonatal Apgar score, birth weight and admission neonatal intensive care unit between the two groups

\begin{tabular}{|c|c|c|c|}
\hline Variables & $\begin{array}{l}\text { IG (48) } \\
\text { No. (\%) }\end{array}$ & $\begin{array}{l}\text { CG (49) } \\
\text { No. (\%) }\end{array}$ & -P- Value \\
\hline $\begin{array}{l}\begin{array}{l}\text { APGAR Score } \\
<7 \text { Score } \\
7>\text { Score }\end{array} \\
\end{array}$ & $\begin{array}{l}45(93.8) \\
3(6.3\end{array}$ & $\begin{array}{l}35(71.4) \\
14(28.6)\end{array}$ & 0.004 \\
\hline $\begin{array}{l}\text { Birth weight / g } \\
<2500 \\
2500 \text { to }<4000 \\
\geq 4000\end{array}$ & $\begin{array}{l}1(2.1) \\
43(89.6) \\
4(8.3)\end{array}$ & $\begin{array}{l}1(2.1) \\
44(89.8) \\
4(8.2)\end{array}$ & 1.000 \\
\hline $\begin{array}{l}\text { ANICU } \\
\text { Yes } \\
\text { No } \\
\end{array}$ & $\begin{array}{l}4(8.3) \\
44(91.7)\end{array}$ & $\begin{array}{l}16(32.7) \\
33(67.3)\end{array}$ & 0.003 \\
\hline
\end{tabular}

IG: Intervention group, CG: Control group, g: gram, ANICU: Admission neonatal intensive care unit 


\section{Discussion}

This study was carried out to determine the effect of antenatal exercise on neonatal outcomes during the delivery process. In the present study, the novel program was studied, the lower limbs relaxed, sitting on the birth ball, Kegel exercises (pelvic floor exercise), and breathing exercise and relaxation during labor are new phenomena for the pregnant women in Kurdish culture. Through this program were oriented the pregnant women about the importance of antenatal exercise and the effect of antenatal exercise on the neonatal outcome and their health wellbeing during delivery. The studies related antenatal exercise is limited but suggests that moderate exercise during uncomplicated pregnancy does not lead to adverse outcomes for the fetus and improves overall neonatal health well-being 12,13,14,15.

The present study showed that the fetal heart normal range $120-160 \mathrm{bpm}$ in the intervention group were higher than the control group, which a statistically significant difference between two groups $(\mathrm{P}<0.01)$. Found a higher percentage of the fetal heart rate (less or above normal range $120-160 / \mathrm{bpm})$ in the control group $(17.4 \%$ vs. $2.1 \%$ ) respectively, the reason for abnormal fetal heart rate during delivery in the control group are due to prolonged labor, hypoxia and meconium ${ }^{14}$. Concerning the fetal complication, fetal distress was less reported during labor, also the rate of fetal distress in intervention group less than the control group. The reasons of fetal distress are due to prolonged labor, lack of fetal head descent into the pelvis, incomplete rotation of the fetal head hypoxia and meconium ${ }^{14,16}$.

Another appealing finding in this study is that the Apgar score was higher in the intervention group compared to the control group at the first minute $2,8,15$. Miquelutti et al and Nascimen to disagrees with the result of the present study, found that exercise during pregnancy has no effect and no significant difference between intervention and control groups regarding the Apgar score at first minute ${ }^{17,18}$. Regarding birth weight, in the present study, we did not find a statistically significant difference in birth weight between intervention and control groups, we observed that the prevalence of newborns with birth weight between 2500 to $<4000 \mathrm{~g}$ was $89.6 \%(\mathrm{n}=43)$ in the intervention group vs. $89.8 \%(\mathrm{n}=44)$ in the control group, also was no a statistically significant difference between groups in low birth weight $(<2500 \mathrm{~g})$ or macrosomia $(<4000 \mathrm{~g})$. The results of some studies are agreement with the present study findings $2,7,14,18,19,20,21,22,23$ there are found that performing the exercise during pregnancy has no effect on birth weight.

We also found that the pregnant women performed of antenatal exercises had a significant association with their newborn admission to neonatal intensive care unit. The rate of referring newborn to neonatal intensive care unit in the intervention group less than the rate of neonatal admission in intensive care unit in a control group. $8.3 \%(\mathrm{n}=4)$ in the intervention group vs. $32.7 \%$ $(n=16)$ in the control group needed admission to the neonatal intensive care unit after birth. were due to meconium aspiration, asphyxia ${ }^{17}$.

\section{Conclusion}

Antenatal exercise is recommended for healthy pregnant women as a safe and effective strategy for enhancing fetal and newborn outcomes (fetal heart rate, fetal complications during delivery, Apgar score and reduced birth weight and admission neonatal intensive care unit)

\section{Conflict of Interests: None}

Ethical Clearance: This perspective - intervention study, was approved by the Ethics Committee in the College of Nursing, Hawler Medical University (Registration No:8) and the Directorate of health in Erbil City, Kurdistan Region, Iraq.

Source of Funding: myself

\section{References}

1. Nascimento SL, Surita FG, Cecatti JG . Physical exercise during pregnancy:a systematic review. Curr Opin Obstet Gynecol 2012, 24:387-394 DOI:10.1097/ GCO.0b013e328359f131

2. Murtezani A, Ibraimi $Z$ et al.The impact of exercise during pregnancy on neonatal outcomes: a randomized controlled trial. J SPORTS MED PHYS FITNESS; 2014, 54:802-8.

3. Haakstad, L A, Bo K. Exercise in pregnant women and birth weight. a randomized controlled trial. BMC Pregnancy, Childbirth 2011,11, 66.

4. Davies GA, Wolfe LA, Mottola MF, et al. Society of Obstetricians and gynecologists of Canada, SOGC Clinical Practice Obstetrics Committee. Joint SOGC/CSEP clinical practice guideline: Exercise in pregnancy and the postpartum period. 
Can J Appl Physiol; 2003, 28(3):330-41.

5. Committee on Obstetric Practice. ACOG Committee Opinion. Exercise during pregnancy and the postpartum period. Number 267, January. American College of Obstetricians and Gynecologists. Int J Gynaecol Obstet; 2002, 77(1):79-81.

6. Moyer C, Livingston $\mathrm{J}$, et al (2015). Influence of exercise mode on pregnancy outcomes. ENHANCED by Mom project. BMC Pregnancy \& Childbirth, 15(1), 1.

7. Seneviratne SN, Jiang Y, Derraik JGB, et al. Effects of antenatal exercise in overweight and obese pregnant women on maternal and perinatal outcomes. a randomised controlled trial. Royal College of Obstetricians and Gynaecologists; 2015, DOI: 10.1111/1471-0528.13738

8. Gehana AA. Khadiga S.A. Amir G.A. et al . Efficacy of antenatal exercises on maternal and neonatal outcomes in elderly primigravida. Kasr Al Ainy Medical Journal 2015, DOI: 10.4103/16874625.177813.

9. Barakat R, Lucia A, Ruiz JR. Resistance exercise training during pregnancy and newborn's birth size. a randomised controlled trial. International Journal of Obesity. 2009, 33:1048-1057

10 .Chasan-Taber L, Evenson KR, Sternfeld B et al. Assessment of recreational physical activity during pregnancy in epidemiologic studies of birthweight and length of gestation: methodologic aspects. Women Health. 2007, 45(4):85-107

11. Bell R, O’Neill M. Exercise and Pregnancy: A Review.2007, 21(2):85-95

12. Megann EF, Evans SHF, Weitz BRN, et al. Antepartum, Intrapartum, and Neonatal Significance of Exercise on Healthy Low-Risk Pregnant Working Women. Obstetrics \& Gynecology; 2002, 99(3):466-472

13. Clapp JF, Capeless EL. Neonatal morphometrics after endurance exercise during pregnancy. Am J Obstet Gynecol; 1990, 163:1805-1811

14. Rad LS \& Jahanshiri A. Effect of a period of exercise during pregnancy on certain delivery parameters. Euro. J. Exp. Bio, 2013, 3(2):78-85

15. Sibley L, Ruhling RO. Swimming and physical fitness during pregnancy. J Nurse Midwifery;1981, 26:3-12

16. Mirzakhani K, Hejazinia Z, Golmakani N et al. The Effect of Birth Ball Exercises during Pregnancy on Mode of Delivery in Primiparous Women. Journal of Midwifery and Reproductive Health. 2015; 3(1): 269-275.

17. Miquelutti MA, Cecatti JG, Makuch M. Evaluation of a birth preparation program on lumbopelvic pain, urinary incontinence, anxiety and exercise: a randomized controlled trial. BMC Pregnancy and Childbirth 2013,13:154.

18. Nascimento SL, Surita, FG, Parpinelli MA. The effect of an antenatal physical exercise programme on maternal/ perinatal outcomes and quality of life in overweight and obese pregnant women: Randomized clinical trial. BJOG;2011, 118:14551463.

19. Szymanski LM, Satin AJ. Exercise During Pregnancy: Fetal Responses to Current Public Health Guidelines. Obstet Gynecol; 2012, 119(3): 603-610.

20. Toosi M, Akbarzadeh M. The Effect of Aerobic Exercises on Maternal Outcomes: A Randomized Controlled Clinical Trial. Women's Health Bull; 2016, 3(4): e31337.

21. Forouhari S, Yazdanpanahi Z, Parsanezhad ME et al. The Effects of Regular Exercise on Pregnancy Outcome, IRCMJ; 2009, 11 (1): 57-60

22. Garnaes KK, Nyrnes SA, Salvesen KA et al. Effect of supervised exercise training during pregnancy on neonatal and maternal outcome among overweight and obese women. Secondary analyses pf the ETIP trial: A randomized controlled. PloS ONE; 2017, 12(3): e0173937.

23. Hickman, S. The effects of exercise during pregnancy and postpartum. 2007, 